\title{
Impact of mash feeding versus pellets on propionic/butyric acid levels and on total Escherichia coli load in the gastrointestinal tract of growing pigs ${ }^{1}$
}

\author{
J. Longpré, $* \dagger §$ J. M. Fairbrother, $\uparrow+\S$ P. Fravalo, $* \dagger+$ J. Arsenault, $\dagger+$

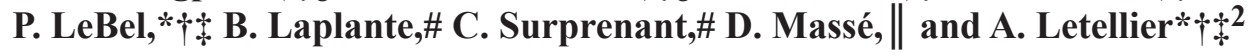

\begin{abstract}
*NSERC Industrial Research Chair in Meat Safety, Department of Pathology and Microbiology, Université de Montréal, Faculty of Veterinary Medicine, Saint-Hyacinthe, Quebec, Canada, J2S 7C6; †Swine and Poultry Infectious Diseases Research Centre, Department of Pathology and Microbiology, Université de Montréal, Faculty of Veterinary

Medicine, Saint-Hyacinthe, Quebec, Canada, J2S 7C6; \$Groupe de Recherche et D’enseignement en Salubrité Alimentaire (GRESA), Department of Pathology and Microbiology, Université de Montréal, Faculty of Veterinary Medicine, Saint-Hyacinthe, Quebec, Canada, J2S 7C6; §OIE Reference Laboratory for Escherichia coli (EcL), Department of Pathology and Microbiology, Université de Montréal, Faculty of Veterinary Medicine, Saint-Hyacinthe, Quebec, Canada, J2S 7C6; \#F. Ménard Inc., Ange-Gardien, Quebec, Canada, J0E 1E0; and \|Dairy and Swine Research and Development Center, Agriculture and Agri-food Canada, Sherbrooke, Quebec, Canada, J1M 0C8
\end{abstract}

\begin{abstract}
Feed characteristics may influence the bacterial community composition and metabolic activities in the pig gastrointestinal tract, known to be associated with positive effects on the gut. Use of mash feed is associated with reduced Salmonella excretion, but little is known of its effect on the Escherichia coli population or of the mechanism of action. Our objectives were to assess the effect of feed texture combined with feed particle size on VFA profiles and levels, total E. coli count, and the presence of genes encoding virulence factors of pathogenic $E$. coli strains in the digestive tract along with their impact on pig performance of fattening pigs. Pigs $(n=840)$ on a commercial farm received mash or pellet diets of different particle sizes during the fattening period. Caecal and colon contents from 164 pigs were sampled at the slaughterhouse for enumeration of $E$. coli by quantitative PCR (qPCR) and for VFA quantification by capillary gas chromatography. The $y c c T$ gene was used to enumerate total $E$. coli. Improved pig performances associated with pellet texture and a $500-\mu \mathrm{m}$ size were observed. Caecal $(P=$
\end{abstract}

$0.02)$ and colon $(P<0.01)$ propionic acid concentrations were lower for pigs receiving pellet rather than mash feed. Similarly, caecal $(P=0.01)$ and colon $(P<$ $0.001)$ butyric acid concentrations were also lower for pigs receiving pellet rather than mash feed, as determined by capillary gas chromatography. Moreover, caecal $(P=0.03)$ and colon $(P<0.001)$ butyric acid concentrations were higher for pigs receiving a feed with a $1,250-\mu \mathrm{m}$ particle size rather than a $500-\mu \mathrm{m}$ particle size. On the other hand, total caecal and colon $E$. coli levels were higher for pigs receiving pellet feed than for those receiving mash feed. For total E. coli enumeration, caecal $(P<0.01)$ and colon $(P<0.01)$ $y c c T$ gene copies were higher for pigs receiving pellet rather than mash feed. No effect of particle size on fatty acid concentrations or on $E$. coli numbers was observed. Virulence gene quantification revealed no trend. Taken together, results showed that mash feed is associated with lower growth performance but with favorable intestinal changes linked to VFA levels and $E$. coli reduction in the intestine.

Key words: Escherichia coli, feed particle size, feed texture, pigs, pig performance, volatile fatty acid

(C) 2016 American Society of Animal Science. All rights reserved. J. Anim. Sci. 2016.94:1053-1063 doi:10.2527/jas2015-9617

\footnotetext{
${ }^{1}$ We thank Guy Maynard and Martine Messier (Research and Development, F. Ménard Inc., Ange-Gardien, QC) for technical help at the farm and the slaughterhouse and Denis Deslauriers (Dairy and Swine Research and Development Center, Agriculture and Agri-Food Canada, Lennoxville, QC) for conducting the gas chromatograph analysis. We also thank the Natural Sciences and Engineering Research
}

Council (NSERC) of Canada, Financial partners in the Industrial Research chair in meat safety, and the Swine and Avian Infectious Disease Research Centre (CRIPA) for funding this study.

${ }^{2}$ Corresponding author: ann.letellier@umontreal.ca

Received July 28, 2015.

Accepted January 1, 2016. 


\section{INTRODUCTION}

Foodborne diseases are still a major public health concern, as many etiological agents may be zoonotic and their control on farms can be quite challenging. Moreover, antimicrobials are commonly used to control bacterial infections at the farm level, generating public health concerns. Changes in feed characteristics, such as the use of nonpelleted rather than pelleted feed or different particle sizes, may enhance pig gastrointestinal tract health, reduce Salmonella spp. prevalence, and influence pig performance (Lo Fo Wong et al., 2004; O'Connor et al., 2008). However, this has not yet been clearly confirmed in field conditions, and the mechanism of action is still unknown. In addition, no data are available regarding the effect of feed characteristics on Escherichia coli populations. For instance, dietary modifications resulting in a modulation of the bioregulation of VFA can have a potential impact on the intestinal microflora (Knudsen et al., 2003). It has been recognized for some time that VFA, such as acetic, propionic, butyric, valeric, and lactic acids, have antibacterial activity. Propionic and butyric acids are particularly important metabolites because of their specific inhibition of enteric bacteria such as Salmonella spp. and because of their general antibacterial effects on $E$. coli in pigs (Hedemann et al., 2005; Stecher and Hardt, 2011). The aim of this study was to investigate the effect of feed texture (mash versus pellet) combined with particle size ( $500 \mu \mathrm{m}$ vs. $750 \mu \mathrm{m}$ vs. $1,250 \mu \mathrm{m})$ on VFA profiles and levels, total $E$. coli, and genes encoding virulence factors of pathogenic E. coli in the digestive tract. As a secondary objective, the performance of fattening pigs was also evaluated with respect to the different diets.

\section{MATERIALS AND METHODS}

\section{Animals and Diets}

This study was conducted with an integrated pig production company owning feed mills, farms, a slaughterhouse, and animal transportation trucks. A total of 840 crossbred Duroc-Yorkshire-Landrace fattening pigs from an all-in all-out commercial herd in Québec, Canada, were distributed in 84 pens ( 5 females and 5 males per pen). Each pen received 1 of 6 different diets (mash feed 500,750 , or $1,250 \mu \mathrm{m}$ and pellet feed 500,750 , or $1,250 \mu \mathrm{m})$, resulting in 14 pens (140 pigs) allocated to each diet. Diets were assigned randomly for each pen at the beginning of the assay ( $55 \mathrm{~d}$ of age) and were maintained until the end of the fattening period (120 d later) in a commercial production unit. Each pig had $2.29 \mathrm{~m}^{2}$ of space. Formulation of each of the 6 different diets was the same (Appendix). Only the feed texture and/or the feed particle size were variable. Particle size of the diets was determined by using a Tyler Ro-Tap shaker machine with sieve stack (W.S. Tyler, Mentor, OH) las recommended by the American Society of Agricultural and Biological Engineers (ASABE; Standard, 2003). Four diet formulations were given over the fattening period: the prestarter formulation was fed from $\mathrm{d} 1$ to 21 , the starter was fed from d 22 to 46 , the grower was fed from d 47 to 88 , and the finisher was fed from d 89 to the end (d 120) according to common commercial feeding practices. All pigs were weighed at each change of formulation, and the feed consumption data were collected. Feed consumption was estimated by the amount of feed used divided by the number of pigs per pen. All procedures were approved by the ethics committee on animal use of the Universite de Montréal based on the guidance of the Canadian Council on Animal Care (CCAC).

\section{Sample Collection}

After a transport to the slaughterhouse early in the morning and a lairage of $2 \mathrm{~h}$ in cleaned pens, the pigs were slaughtered as the first batch of the day. Ileal, cecal, and colon contents from 164 pigs were sampled individually, with pigs being selected from each pen and followed until the end of the assay. More specifically, 2 pigs ( 1 male and 1 female) were selected per pen. However, some pigs could not be sampled because they had died previously at the farm or because they were condemned by an inspector at the slaughterhouse. Intestinal contents were collected using 2 conical $15-\mathrm{mL}$ plastic tubes. For each sample, 1 tube was filled and stored at $-20^{\circ} \mathrm{C}$ for analysis of VFA and the other tube was stored at $-80^{\circ} \mathrm{C}$ for subsequent DNA extraction for quantitative PCR (qPCR) analyses of individual samples of cecal and colon contents. Following the period of fasting, the gastrointestinal tract of the pigs was almost empty, especially the ileum. It was decided to use the small amount of ileum content for the VFA quantification. In addition, cecum and colon are associated with an increase risk of contamination at the slaughterhouse during evisceration.

\section{Volatile Fatty Acids Analysis}

Samples of ileal, caecal, and colon contents from 164 pigs were thawed at $4^{\circ} \mathrm{C}$ overnight, and $4 \mathrm{~g}$ of each sample was weighed into a centrifuge tube containing $6 \mathrm{~g}$ of deionized water. Tubes were centrifuged at $38,724 \times g$ for $30 \mathrm{~min}$. Then, $0.25 \mathrm{~mL}$ of sulfuric acid 0.5 $M$ was added to $1.30 \mathrm{~g}$ of supernatant. The suspension was vortexed and centrifuged at $13,793 \times g$ for $15 \mathrm{~min}$. The supernatants $(0.5 \mathrm{~mL})$ were separated and mixed with $0.5 \mathrm{~mL}$ of an internal standard (2-ethylbutyric). Resin Dowex 50WX8 from Sigma-Aldrich (0.2 g; 
Table 1. Oligonucleotide primers used for multiplex PCR

\begin{tabular}{|c|c|c|c|c|c|c|c|}
\hline $\begin{array}{l}\text { Virulence } \\
\text { factor }\end{array}$ & Gene & $\begin{array}{c}\text { Accession } \\
\text { no. }\end{array}$ & Orientation $^{1}$ & $\begin{array}{l}\text { Primer sequence } \\
\qquad(5 \not-3 \phi)\end{array}$ & $\begin{array}{l}\text { Size of PCR } \\
\text { product, bp }\end{array}$ & $\begin{array}{c}\text { Annealing } \\
\text { temperature, }{ }^{\circ} \mathrm{C}\end{array}$ & Reference \\
\hline \multirow[t]{2}{*}{ LT } & \multirow[t]{2}{*}{ eltB } & \multirow[t]{2}{*}{ J01646 } & $\mathrm{F}$ & TTACGGCGTTACTATCCTCTCTA & \multirow[t]{2}{*}{275} & \multirow[t]{2}{*}{60} & \multirow{2}{*}{$\begin{array}{l}\text { Furrer et } \\
\text { al., } 1990\end{array}$} \\
\hline & & & $\mathrm{R}$ & GGTCTCGGTCAGATATGTGATTC & & & \\
\hline \multirow[t]{2}{*}{$\mathrm{STa}$} & \multirow[t]{2}{*}{ estA } & \multirow[t]{2}{*}{ M58746 } & $\mathrm{F}$ & TCCССТCTTTTAGTCAGTCAACTG & \multirow[t]{2}{*}{163} & \multirow[t]{2}{*}{60} & \multirow{2}{*}{$\begin{array}{l}\text { Ojeniyi et } \\
\text { al., } 1994\end{array}$} \\
\hline & & & $\mathrm{R}$ & GCACAGGCAGGATTACAACAAAGT & & & \\
\hline \multirow[t]{2}{*}{$\mathrm{STb}$} & \multirow[t]{2}{*}{ est $B$} & \multirow[t]{2}{*}{ M35586 } & $\mathrm{F}$ & GCAATAAGGTTGAGGTGAT & \multirow[t]{2}{*}{368} & \multirow[t]{2}{*}{60} & \multirow{2}{*}{$\begin{array}{l}\text { Lortie et al., } \\
1991\end{array}$} \\
\hline & & & $\mathrm{R}$ & GCCTGCAGTGAGAAATGGAC & & & \\
\hline \multirow[t]{2}{*}{$\mathrm{F} 4$} & \multirow[t]{2}{*}{ fae $G$} & \multirow[t]{2}{*}{ M29374 } & $\mathrm{F}$ & ATCGGTGGTAGTATCACTGC & \multirow[t]{2}{*}{601} & \multirow[t]{2}{*}{60} & \multirow{2}{*}{$\begin{array}{l}\text { Ojeniyi et } \\
\text { al., } 1994\end{array}$} \\
\hline & & & $\mathrm{R}$ & AACCTGCGACGTCAACAAGA & & & \\
\hline \multirow[t]{2}{*}{ Stx1 } & \multirow[t]{2}{*}{ stxa } & \multirow[t]{2}{*}{ M19437 } & $\mathrm{F}$ & TTAGACTTCTCGACTGCAAAG & \multirow[t]{2}{*}{531} & \multirow[t]{2}{*}{60} & \multirow{2}{*}{$\begin{array}{l}\text { Woodward } \\
\text { et al., } 1992\end{array}$} \\
\hline & & & $\mathrm{R}$ & TGTTGTACGAAATCCCCTCTG & & & \\
\hline \multirow[t]{2}{*}{ Stx2 } & \multirow[t]{2}{*}{ Stx $2 A$} & \multirow[t]{2}{*}{ X07865 } & $\mathrm{F}$ & TTATATCTGCGCCGGGTCTG & 327 & 60 & Woodward \\
\hline & & & $\mathrm{R}$ & AGACGAAGATGGTCAAAACG & & & et al., 1992 \\
\hline EAE & eae & U66102 & $\mathrm{F}$ & CATTATGGAACGGCAGAGGT & 791 & 60 & Beaudry et \\
\hline & & & $\mathrm{R}$ & ATCTTCTGCGTACTGCGTTCA & & & al., 1996 \\
\hline CNF $1 / 2$ & $c n f$ & U42629 & $\mathrm{F}$ & TCGTTATAAAATCAAACAGTG & 446 & 55 & Ewers et \\
\hline & & & $\mathrm{R}$ & CTTTACAATATTGACATGCTG & & & al., 2007 \\
\hline $\mathrm{P}$ & papC & M30806 & $\mathrm{F}$ & TGATATCACGCAGTCAGTAGC & 501 & 55 & Ewers et \\
\hline & & & $\mathrm{R}$ & CCGGCCATATTCACATAAC & & & al., 2007 \\
\hline Aerobactin & $i u c D$ & M18968 & $\mathrm{F}$ & AAGTGTCGATTTTATTGGTGTA & 778 & 60 & Herrero et \\
\hline & & & $\mathrm{R}$ & CCATCCGATGTCAGTTTTCTG & & & al., 1988 \\
\hline Tsh & tsh & L27423 & $\mathrm{F}$ & GGTGGTGCACTGGAGTGG & 640 & 55 & Dozois et \\
\hline & & & $\mathrm{R}$ & AGTCCAGCGTGATAGTGG & & & al., 2000 \\
\hline F18 & F18 & M61713 & $\mathrm{F}$ & GTGAAAAGACTAGTGTTTATTTC & 510 & 60 & Ngeleka et \\
\hline & & & $\mathrm{R}$ & CTTGTAAGTAACCGCGTAAGC & & & al., 2003 \\
\hline
\end{tabular}

\footnotetext{
${ }^{1} \mathrm{~F}=$ forward; $\mathrm{R}=$ reverse.
}

Oakville, Ontario Canada) was added to each sample. Tubes were then gently vortexed, and the suspension was filtered using a BD Luer-Lok 3-mL syringe with a $25-\mathrm{mm}$ Syringe Filter with $0.45 \mu \mathrm{m}$ cellulose (VWR International, Mississauga, ON). All of the vials were kept at $4{ }^{\circ} \mathrm{C}$ until they were analyzed with the chromatograph. The VFA (acetic, propionic, butyric, isobutyric, isovaleric, and valeric) concentrations were measured using a PerkinElmer gas chromatograph model 8,310 (PerkinElmer, Waltham, MA) equipped with a DBFFAP high resolution column.

\section{Multiplex PCR Analysis}

Samples from cecal and colon contents were enriched in Luria-Bertani broth overnight at $37^{\circ} \mathrm{C}$, and DNA templates were prepared from the resulting enrichments by heat lysis. Twelve virulence genes (Table 1) defining the $E$. coli pathotypes found in animals were selected for use in our study (Herrero et al., 1988; Furrer et al., 1990; Lortie et al., 1991; Woodward et al., 1992; Ojeniyi et al., 1994; Beaudry et al., 1996; Dozois et al., 2000; Ngeleka et al., 2003; Ewers et al., 2007). Four multiplex PCR procedures were performed according to a protocol of the Reference Laboratory for Escherichia coli (EcL, Faculty of Veterinary Medicine from the Université de Montréal) available at http:// www.apzec.ca/en/APZEC/Protocols/APZEC_PCR_ en.aspx with slight modifications (Maluta et al., 2014).

\section{Quantitative PCR}

For qPCR, total DNA was extracted from cecal and colon contents of pigs by the use of a physical-chemical method with phenol-chloroform, essentially as previously described with a few modifications (Juteau et al., 2004). Briefly, cells were disrupted in FastPrep Lysing Matrix tubes using the FastPrep-24 Instrument (MP Biomedicals, Solon, OH). The DNA was purified by phenol-chloroform-isoamyl alcohol extraction and precipitated with ethanol. DNA was quantified using a NanoDrop ND-1000 Spectrophotometer (ND1000 V3.1.2; NanoDrop products, Wilmington, DE). The qPCR was performed on an Eco Real-Time PCR system (Illumina, San Diego, CA) using the Eco Software (version 4.1). Each reaction was run in triplicate in a volume of $20 \mu \mathrm{L}$. The reaction mixture consisted of 4 $\mu \mathrm{L}$ of MBI EVOlution EvaGreen qPCR master mixes (Montreal Biotech Inc., Dorval, Canada), $1 \mu \mathrm{L}$ (10 $\mathrm{m} M$ ) of primers (Table 2), $9 \mu \mathrm{L}$ of sterilized water, and $5 \mu \mathrm{L}(10 \mathrm{ng} / \mu \mathrm{L})$ of DNA of cecal or colon contents. Amplification involved 1 cycle at $95^{\circ} \mathrm{C}$ for $10 \mathrm{~min}$ 
Table 2. Oligonucleotide primers used for quantitative PCR

\begin{tabular}{|c|c|c|c|c|c|c|c|}
\hline $\begin{array}{l}\text { Targeted bacterial species } \\
\text { or virulence factor }\end{array}$ & Gene & $\begin{array}{l}\text { Accession } \\
\text { no. }\end{array}$ & Orientation $^{1}$ & $\begin{array}{l}\text { Primer sequence } \\
\left(5^{\prime}-3^{\prime}\right)\end{array}$ & $\begin{array}{l}\text { Size of PCR } \\
\text { product, bp }\end{array}$ & $\begin{array}{c}\text { Annealing } \\
\text { temperature, }{ }^{\circ} \mathrm{C}\end{array}$ & Reference \\
\hline \multirow[t]{2}{*}{ E. coli } & \multirow[t]{2}{*}{$y c c T$} & \multirow[t]{2}{*}{ EG13722 2} & $\mathrm{~F}$ & GCATCGTGACCACCTTGA & \multirow[t]{2}{*}{59} & \multirow[t]{2}{*}{56} & \multirow{2}{*}{$\begin{array}{l}\text { Clifford et } \\
\text { al., } 2012\end{array}$} \\
\hline & & & $\mathrm{R}$ & CAGCGTGGTGGCAAAA & & & \\
\hline \multirow[t]{2}{*}{ CNF1 } & \multirow[t]{2}{*}{ cnfl } & \multirow[t]{2}{*}{ U42629 } & $\mathrm{F}$ & TTAAGGGTTCTGGAAGCTTTGG & \multirow[t]{2}{*}{194} & \multirow[t]{2}{*}{61} & \multirow[t]{2}{*}{ Our study } \\
\hline & & & $\mathrm{R}$ & CATCTGCACTGTTAACATTTGAGG & & & \\
\hline \multirow[t]{2}{*}{$\mathrm{STb}$} & \multirow[t]{2}{*}{ est $B$} & \multirow[t]{2}{*}{ M35586 } & $\mathrm{F}$ & CTTCTTGCATCTATGTTCGT & \multirow[t]{2}{*}{107} & \multirow[t]{2}{*}{54} & \multirow[t]{2}{*}{ Our study } \\
\hline & & & $\mathrm{R}$ & АCTTTCCTTGGCTATTTGTC & & & \\
\hline \multirow[t]{2}{*}{ F4 } & \multirow[t]{2}{*}{ fae $G$} & \multirow[t]{2}{*}{ M29374 } & $\mathrm{F}$ & AATGCATCTTATGCCGGTG & \multirow[t]{2}{*}{163} & \multirow[t]{2}{*}{61} & \multirow{2}{*}{$\begin{array}{l}\text { Stahl et al., } \\
2011\end{array}$} \\
\hline & & & $\mathrm{R}$ & TCTTTGAATCTGTCCGAGAATATC & & & \\
\hline
\end{tabular}

\footnotetext{
${ }^{1} \mathrm{~F}=$ forward; $\mathrm{R}=$ reverse.

${ }^{2}$ EcoGene accession number.
}

for initial denaturation followed by 40 cycles of denaturation at $95^{\circ} \mathrm{C}$ for $15 \mathrm{~s}$, primer annealing at optimal temperatures (Table 2) for $15 \mathrm{~s}$ (except for fimbriae $\mathrm{F} 4$ $45 \mathrm{~s}$ ), and extension at $72^{\circ} \mathrm{C}$ for $15 \mathrm{~s}$. All standard curves were constructed using PCR products. To quantify total $E$. coli by $\mathrm{qPCR}$, serial dilutions of DNA from $10^{8}$ to $10^{2}$ copies were prepared and tested in triplicate. Primer efficiency was $96.68 \%$ with an $R^{2}$ value of 0.989 .

\section{Statistical Analysis}

Pig performance parameters (ADFI, ADG, and feed conversion ratio [FCR]) were calculated for each pen using the average pig BW, quantity of feed distributed, and the number of pigs. Multiple linear regression analyses were used for the analysis of each VFA, qPCR data, and pig performance, whereas multiple logistic regressions were used for PCR data (positive/negative) and gastric lesion (positive/negative) data. The unit of analysis was the pig, except for the performances for which it was the pen. For qPCR, data were log-transformed to scope normality. For gastric lesions, a first model was used to evaluate if the presence of ulcers vs. hyperkeratosis was associated with feed texture and particle size. In the absence of significant association, the 2 lesions were combined for modeling; otherwise, a separate model was performed for hyperkeratosis (positive/negative) and ulcers (positive/ negative). The feed texture and feed particle size were included as categorical explanatory variables in all models. Their interaction was tested and was only kept in the model if statistically significant $(P<0.05)$. For VFA and qPCR data models, the pen was added as a random effect to account for potential clustering of pigs within each pen. For PCR data, estimates were also adjusted for clustering within pen using generalized estimating equations. This pen correlation effect was not considered for pig performance analyses, as the unit of analysis was the pen, or for the ulcer data, as the information on the pen of origin was not available. Residual plots were used to assess the fit of the models and to detect the presence of outliers. Least squares means or predicted probabilities were used to present the results. All statistical analyses were performed in SAS software version 9.3 (SAS Inst. Inc., Cary, NC).

\section{RESULTS}

\section{Effect of Feed Texture and Particle Size on VFA Levels in the Intestinal Contents of Pigs}

Feeding of mash to the pigs resulted in a significant increase in levels for many VFA in the cecum and colon contents compared to feeding of pellets (Table 3). Propionic and butyric acid levels were significantly greater in both the cecum and colon contents of pigs receiving the mash feed than they were in the cecum and colon contents of those receiving the pellet feed (Table 3). In addition, the valeric acid level was significantly higher in the colon contents but not in the cecum contents of pigs receiving the mash feed than it was in the colon contents of those receiving the pellet feed. With respect to the feed particle size, colon isobutyric and isovaleric acid levels were higher for the $500-\mu \mathrm{m}$ and $750-\mu \mathrm{m}$ diets than for the $1,250-\mu \mathrm{m}$ diet. Moreover, a significant interaction between feed texture and particle size was observed in relation to colon butyric acid levels (data not shown). Indeed, colon butyric acid levels for the mash $1,250-\mu \mathrm{m}$ diet were significantly higher than those for all of the other diets $(24.7 \pm 2.0 \mathrm{mmol} / \mathrm{L}$ versus $\leq 18.8 \pm 2.3 \mathrm{mmol} / \mathrm{L} ; P<0.05)$. For all other models, the interaction between feed particle size and feed texture was not statistically significant (all $\mathrm{P}$ values were $>0.05$; data not shown). VFA levels in the ileum were similar for all feed textures and feed particle sizes tested.

\section{Effect of Feed Texture and Particle Size on Prevalence of E. coli Virulence Genes in the Intestinal Contents of Pigs}

The detection of the various tested genes did not differ according to particle size or feed texture (all $P$ 
Table 3. Least squares means VFA concentration (mmol/L) \pm SEM according to feed texture and particle size. Propionic and butyric acid concentrations were higher in cecal and colon contents of mash fed animals

\begin{tabular}{|c|c|c|c|c|c|c|c|c|}
\hline \multirow[b]{2}{*}{ VFA and $\mathrm{pH}$} & \multirow[b]{2}{*}{ No. } & \multicolumn{3}{|c|}{ Feed texture } & \multicolumn{4}{|c|}{ Feed particle size } \\
\hline & & $\operatorname{Mash}(n=81)$ & Pellets $(n=83)$ & $P$-value & $500 \mu \mathrm{m}(n=51)$ & $750 \mu \mathrm{m}(n=55)$ & $1,250 \mu \mathrm{m}(n=58)$ & $P$-value \\
\hline \multicolumn{9}{|l|}{ Ileum } \\
\hline Acetic & 163 & $20.53 \pm 1.16$ & $22.80 \pm 1.28$ & 0.16 & $21.05 \pm 1.44$ & $23.08 \pm 1.43$ & $20.87 \pm 1.33$ & 0.47 \\
\hline Propionic & 163 & $2.90 \pm 0.24$ & $2.90 \pm 0.24$ & 0.99 & $2.93 \pm 0.31$ & $3.01 \pm 0.30$ & $2.77 \pm 0.28$ & 0.84 \\
\hline Butyric & 163 & $3.11 \pm 0.24$ & $3.33 \pm 0.24$ & 0.51 & $3.23 \pm 0.30$ & $3.18 \pm 0.30$ & $3.25 \pm 0.28$ & 0.99 \\
\hline Isobutyric & 163 & $0.36 \pm 0.03$ & $0.37 \pm 0.03$ & 0.76 & $0.37 \pm 0.04$ & $0.38 \pm 0.04$ & $0.33 \pm 0.03$ & 0.61 \\
\hline Valeric & 163 & $0.18 \pm 0.02$ & $0.21 \pm 0.02$ & 0.44 & $0.18 \pm 0.03$ & $0.18 \pm 0.03$ & $0.21 \pm 0.03$ & 0.65 \\
\hline Isovaleric & 163 & $0.73 \pm 0.06$ & $0.73 \pm 0.06$ & 0.94 & $0.80 \pm 0.08$ & $0.77 \pm 0.08$ & $0.62 \pm 0.07$ & 0.20 \\
\hline $\mathrm{pH}$ & 147 & $6.98 \pm 0.04$ & $6.99 \pm 0.04$ & 0.84 & $7.03 \pm 0.05$ & $7.04 \pm 0.05$ & $6.89 \pm 0.05$ & 0.07 \\
\hline \multicolumn{9}{|l|}{ Cecum } \\
\hline Acetic & 162 & $86.02 \pm 2.01$ & $82.74 \pm 1.99$ & 0.25 & $84.90 \pm 2.54$ & $86.38 \pm 2.45$ & $81.87 \pm 2.35$ & 0.40 \\
\hline Propionic & 162 & $36.74 \pm 0.99$ & $33.42 \pm 0.98$ & 0.02 & $34.64 \pm 1.25$ & $33.53 \pm 1.20$ & $37.07 \pm 1.16$ & 0.10 \\
\hline Butyric & 162 & $16.29 \pm 0.54$ & $14.28 \pm 0.53$ & 0.01 & $14.25^{\mathrm{a}} \pm 0.68$ & $14.91^{\mathrm{ab}} \pm 0.65$ & $16.70^{\mathrm{b}} \pm 0.63$ & 0.03 \\
\hline Isobutyric & 162 & $2.21 \pm 0.09$ & $2.25 \pm 0.09$ & 0.76 & $2.36 \pm 0.11$ & $2.27 \pm 0.11$ & $2.07 \pm 0.11$ & 0.17 \\
\hline Valeric & 162 & $2.57 \pm 0.08$ & $2.50 \pm 0.08$ & 0.57 & $2.69 \pm 0.10$ & $2.51 \pm 0.10$ & $2.40 \pm 0.09$ & 0.13 \\
\hline Isovaleric & 162 & $2.75 \pm 0.12$ & $2.82 \pm 0.12$ & 0.72 & $2.95 \pm 0.16$ & $2.86 \pm 0.15$ & $2.54 \pm 0.15$ & 0.13 \\
\hline $\mathrm{pH}$ & 145 & $6.40 \pm 0.06$ & $6.51 \pm 0.06$ & 0.21 & $6.55 \pm 0.07$ & $6.46 \pm 0.07$ & $6.35 \pm 0.07$ & 0.16 \\
\hline \multicolumn{9}{|l|}{ Colon } \\
\hline Acetic & 162 & $83.59 \pm 2.04$ & $83.38 \pm 2.04$ & 0.94 & $84.89 \pm 2.47$ & $85.87 \pm 2.47$ & $79.69 \pm 2.41$ & 0.17 \\
\hline Propionic & 162 & $37.05 \pm 1.04$ & $32.29 \pm 1.04$ & $<0.01$ & $33.69 \pm 1.33$ & $33.74 \pm 1.26$ & $36.58 \pm 1.22$ & 0.18 \\
\hline Butyric & 162 & $20.73 \pm 0.64$ & $17.44 \pm 0.64$ & $<0.001$ & $17.62^{\mathrm{a}} \pm 0.83$ & $18.08^{a} \pm 0.78$ & $21.57^{\mathrm{b}} \pm 0.75$ & $<0.001$ \\
\hline Isobutyric & 162 & $3.03 \pm 0.10$ & $2.93 \pm 0.10$ & 0.48 & $3.04^{\mathrm{a}} \pm 0.12$ & $3.15^{\mathrm{a}} \pm 0.12$ & $2.74^{b} \pm 0.12$ & 0.04 \\
\hline Valeric & 162 & $3.02 \pm 0.10$ & $2.56 \pm 0.10$ & $<0.001$ & $2.65 \pm 0.13$ & $2.75 \pm 0.12$ & $2.98 \pm 0.11$ & 0.13 \\
\hline Isovaleric & 162 & $4.18 \pm 0.13$ & $3.95 \pm 0.13$ & 0.21 & $4.07^{\mathrm{ab}} \pm 0.16$ & $4.33^{\mathrm{a}} \pm 0.16$ & $3.78^{b} \pm 0.15$ & 0.04 \\
\hline $\mathrm{pH}$ & 146 & $6.17 \pm 0.04$ & $6.24 \pm 0.03$ & 0.16 & $6.23 \pm 0.04$ & $6.20 \pm 0.04$ & $6.18 \pm 0.04$ & 0.67 \\
\hline
\end{tabular}

${ }^{\mathrm{a}, \mathrm{b}}$ Different superscript letters between subcategories of the feed particles size indicate significant differences $(P<0.05)$ while superscripts of the same letter indicate no significant differences $(P \geq 0.05)$.

$>0.20$ ), with the exception of estA, for which detection was higher in the mash than in the pellet feed $(P$ $=0.02$ ). The faeG, F18, and stxA were not tested due to the absence or very low number of positive samples (data not shown).

\section{Quantitative PCR}

For total E. coli enumeration by real-time PCR (Fig. 1), the number of $y c c T$ log gene copies per gram of cecal contents was higher for pellet-fed than for mash-fed animals $(P<0.01)$. Similarly, the number of $y c c T \log$ gene copies per gram of colon contents was higher for pellet-fed than for mash-fed animals $(P<0.01)$. According to feed particle size, the number of $y c c T$ log gene copies per gram of cecal contents was higher for animals fed the 500- $\mu \mathrm{m}$ diet than for those fed the $750-\mu \mathrm{m} \operatorname{diet}(P<0.05)$. On the other hand, the enumeration of the genes fae $G$, est $B$, and $c n f 1$, amplified for the quantification of virulent $E$. coli populations, showed no differences between the pellet- and the mash-fed animals. Furthermore, feed particle size had no effect on $f a e G$, estB, and cnfl gene enumeration.

\section{Pig Performance Parameters}

Overall, pig performance parameters were significantly greater in pigs receiving pellet feed than in pigs receiving mash feed (Table 4), except in pigs receiving the starter feed formulation, where a similar ADFI was observed for the pellet and the mash diets $(P=0.21)$. For each feed formulation, the FCR of pigs receiving pellet feed were significantly lower $(P<0.001)$ than the FCR of pigs receiving mash feed. With respect to the feed particle size, significant differences were only observed when comparing the FCR and the ADFI of pigs receiving the $500-\mu \mathrm{m}$ feed size with those of pigs receiving the $750-$ or $1,250-\mu \mathrm{m}$ feed size. Cumulative results for particle size from all feed formulations demonstrated that the $500-\mu \mathrm{m}$ feed particle size was associated with a lower FCR than that observed for the 750- and 1,250 - $\mu \mathrm{m}$ feed particle sizes $(P<0.001)$. Also, the ADFI for the $500-\mu \mathrm{m}$ feed particle size was significantly lower than that observed for the 1,250$\mu \mathrm{m}$ feed particle size $(P<0.01)$ Moreover, cumulative results for the 4 different feed formulations showed significant interaction between feed texture and feed particle size with respect to the FCR (data not shown). Thus, the impact of feed texture on the FCR observed 
a)

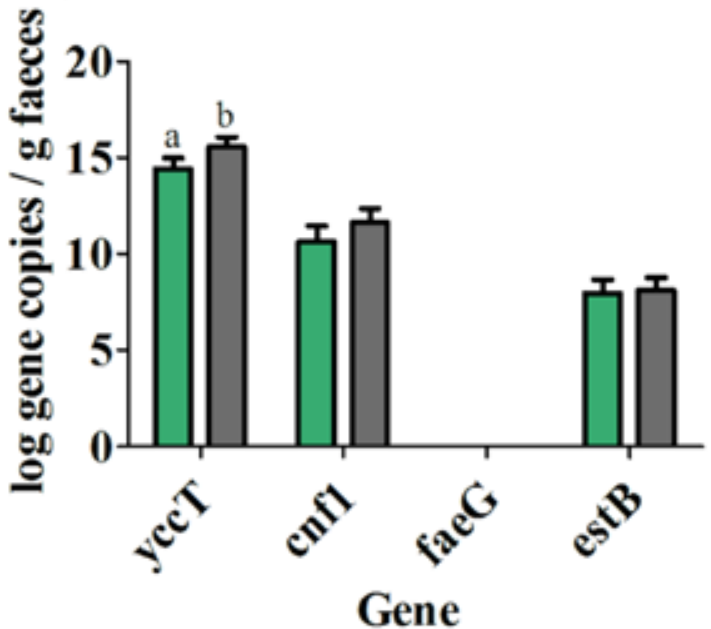

$\square$ Mash $\square$ Pellet

c)

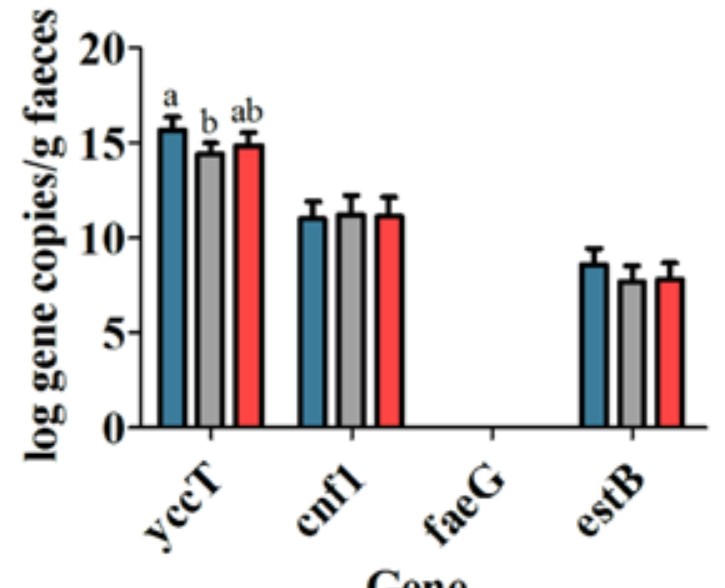

Gene

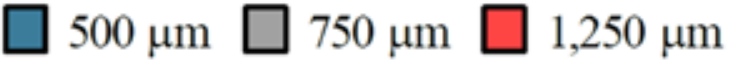

b)

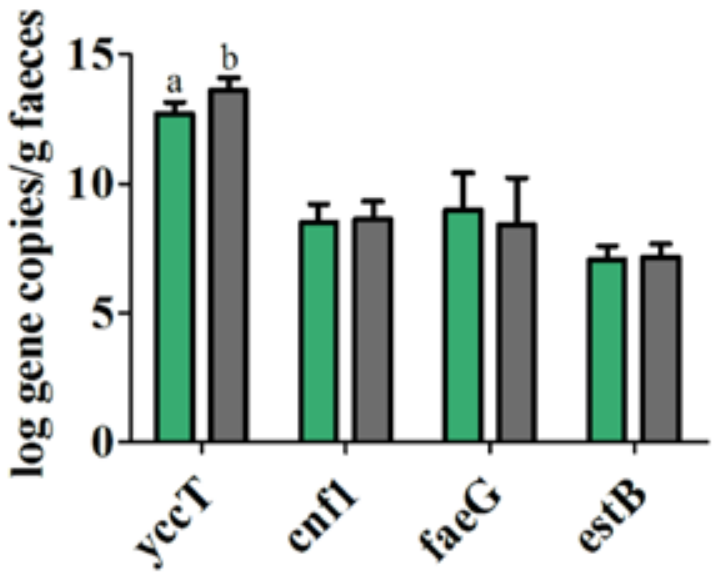

Gene

$\square$ Mash $\square$ Pellet

d)

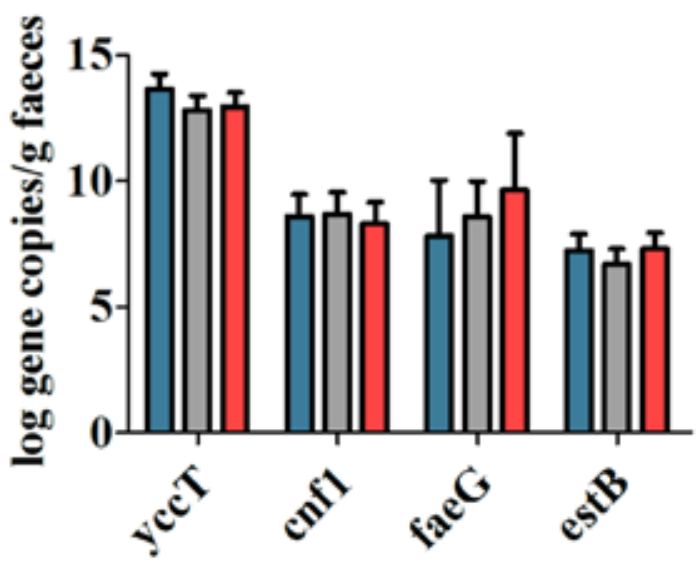

Gene

$500 \mu \mathrm{m} \square 750 \mu \mathrm{m} \square 1,250 \mu \mathrm{m}$

Figure 1. Quantification of specific E. coli genes in cecal and colon contents of animals according to feed texture and particle size diets. (a) Effect of feed texture on cecal E. coli populations. (b) Effect of feed texture on colon E. coli populations. (c) Effect of feed particles size on cecal E. coli populations. (d) Effect of feed particles size on colon E. coli populations. Multiple linear regression SAS 9.3 (SAS Inst. Inc., Cary, NC)—Different superscript letters between subcategories of the feed particles size or feed texture indicate significant differences $(P<0.05)$ while superscripts of the same letter indicate no significant differences $(p \geq 0.05)$.

in pigs receiving the mash $500-\mu \mathrm{m}$ diets was significantly lower than those observed in pigs receiving the mash 750- and mash 1,250- $\mu$ m diets $(P=0.04)$.

\section{Gastric Lesions}

Gastric lesions were evaluated at slaughterhouse in 733 pigs. The presence of stomach hyperkeratosis was noted in 110 pigs (graded as moderate $[n=28]$ or severe $[n=82])$, whereas 189 pigs had gastric ulcers graded as mild $(n=126)$, moderate $(n=42)$, or severe $(n=21)$. The particle size and texture were not as- sociated with the presence of ulcers when compared to hyperkeratosis as the baseline; thus, the 2 lesions were combined for the final model. The presence of gastric lesions (hyperkeratosis or ulcers) was significantly associated with feed particle size and texture; a significant interaction was also observed between the 2 variables (all $P<0.001)$. Overall, the probability of observing gastric lesions was higher with a low particle size and in pellet feed; moreover, the effect for the mash feed was larger in pigs receiving $750-\mu \mathrm{m}$ diets compared to other particle sizes. The predicted probabilities from the model are presented in Fig. 2. 
Table 4. Least squares means \pm SEM of ADG, ADFI, and feed conversion ratio (FCR) according to feed texture and particle size ( $n=84$ pens)

\begin{tabular}{|c|c|c|c|c|c|c|c|}
\hline \multirow{2}{*}{$\begin{array}{l}\text { Feed } \\
\text { formulation }\end{array}$} & \multicolumn{3}{|c|}{ Feed texture } & \multicolumn{3}{|c|}{ Feed particle size } & \multirow[b]{2}{*}{$P$-value } \\
\hline & $\operatorname{Mash}(n=42)$ & Pellets $(n=42)$ & $P$-value & $500 \mu \mathrm{m}(n=28)$ & $750 \mu \mathrm{m}(n=28)$ & $1,250 \mu \mathrm{m}(n=28)$ & \\
\hline \multicolumn{8}{|l|}{ Prestarter } \\
\hline ADG, $\mathrm{kg}$ & $0.684 \pm 0.007$ & $0.711 \pm 0.007$ & 0.01 & $0.707 \pm 0.009$ & $0.693 \pm 0.009$ & $0.694 \pm 0.009$ & 0.49 \\
\hline ADFI, kg & $1.344 \pm 0.011$ & $1.311 \pm 0.011$ & 0.04 & $1.340 \pm 0.0134$ & $1.323 \pm 0.013$ & $1.319 \pm 0.013$ & 0.51 \\
\hline FCR & $1.968 \pm 0.014$ & $1.846 \pm 0.014$ & $<0.001$ & $1.901 \pm 0.018$ & $1.911 \pm 0.018$ & $1.908 \pm 0.018$ & 0.91 \\
\hline \multicolumn{8}{|l|}{ Starter } \\
\hline $\mathrm{ADG}, \mathrm{kg}$ & $0.880 \pm 0.007$ & $0.925 \pm 0.007$ & $<0.001$ & $0.912 \pm 0.008$ & $0.896 \pm 0.008$ & $0.899 \pm 0.008$ & 0.38 \\
\hline ADFI, kg & $2.061 \pm 0.012$ & $2.040 \pm 0.012$ & 0.21 & $2.036 \pm 0.015$ & $2.041 \pm 0.015$ & $2.045 \pm 0.015$ & 0.13 \\
\hline FCR & $2.347 \pm 0.014$ & $2.207 \pm 0.014$ & $<0.001$ & $2.238^{\mathrm{a}} \pm 0.017$ & $2.282^{\mathrm{ab}} \pm 0.017$ & $2.311^{\mathrm{b}} \pm 0.017$ & 0.01 \\
\hline \multicolumn{8}{|l|}{ Grower } \\
\hline $\mathrm{ADG}, \mathrm{kg}$ & $1.021 \pm 0.006$ & $1.048 \pm 0.006$ & $<0.01$ & $1.044 \pm 0.008$ & $1.030 \pm 0.008$ & $1.031 \pm 0.008$ & 0.35 \\
\hline ADFI, kg & $2.875 \pm 0.023$ & $2.776 \pm 0.023$ & $<0.01$ & $2.769^{\mathrm{a}} \pm 0.028$ & $2.839^{\mathrm{ab}} \pm 0.028$ & $2.867^{\mathrm{b}} \pm 0.028$ & 0.05 \\
\hline FCR & $2.817 \pm 0.020$ & $2.650 \pm 0.020$ & $<0.001$ & $2.654^{\mathrm{a}} \pm 0.025$ & $2.761^{b} \pm 0.025$ & $2.786^{\mathrm{b}} \pm 0.025$ & $<0.001$ \\
\hline \multicolumn{8}{|l|}{ Finisher } \\
\hline $\mathrm{ADG}, \mathrm{kg}$ & $0.932 \pm 0.011$ & $0.968 \pm 0.011$ & 0.03 & $0.933 \pm 0.014$ & $0.951 \pm 0.014$ & $0.966 \pm 0.014$ & 0.27 \\
\hline ADFI, kg & $3.104 \pm 0.037$ & $2.892 \pm 0.037$ & $<0.001$ & $2.890^{\mathrm{a}} \pm 0.046$ & $3.007^{\mathrm{ab}} \pm 0.046$ & $3.098^{b} \pm 0.046$ & $<0.01$ \\
\hline FCR & $3.337 \pm 0.034$ & $2.993 \pm 0.034$ & $<0.001$ & $3.101^{\mathrm{a}} \pm 0.042$ & $3.176^{\mathrm{ab}} \pm 0.042$ & $3.218^{\mathrm{b}} \pm 0.042$ & $<0.01$ \\
\hline \multicolumn{8}{|l|}{ Cumulative } \\
\hline ADG, kg & $0.903 \pm 0.004$ & $0.936 \pm 0.004$ & $<0.001$ & $0.923 \pm 0.005$ & $0.915 \pm 0.005$ & $0.919 \pm 0.005$ & 0.57 \\
\hline ADFI, kg & $2.431 \pm 0.016$ & $2.328 \pm 0.016$ & $<0.001$ & $2.334^{\mathrm{a}} \pm 0.019$ & $2.385^{\mathrm{ab}} \pm 0.019$ & $2.420^{\mathrm{b}} \pm 0.019$ & $<0.01$ \\
\hline FCR & $2.648 \pm 0.014$ & $2.448 \pm 0.014$ & $<0.001$ & $2.493^{\mathrm{a}} \pm 0.017$ & $2.564^{\mathrm{b}} \pm 0.017$ & $2.587^{\mathrm{b}} \pm 0.017$ & $<0.001$ \\
\hline
\end{tabular}

${ }^{\mathrm{a}, \mathrm{b}}$ Different superscript letters between subcategories of the feed particles size or feed texture indicate significant differences $(P<0.05)$ while superscripts of the same letter indicate no significant differences $(P \geq 0.05)$.

\section{DISCUSSION}

In the present study, we demonstrate that administration of mash rather than pellet feed is strongly associated with higher intestinal propionic and butyric acid levels, specifically in the colon and cecum contents. The effect of mash feed was specific to propionic and butyric acids, and no significant effects were observed for acetic, isobutyric, valeric, and isovaleric acids. It is possible that mash feeding may promote an increase in bacteria producing specific VFA and, thus, contribute to gastrointestinal health by preventing the proliferation and/or virulence of harmful bacteria such as Salmonella spp. and pathogenic E. coli (Lo Fo Wong et al., 2004; Mikkelsen et al., 2007). LeBel et al. (2013) observed a higher prevalence of Salmonella in the colon of pigs fed with pellet feed in contrast to those fed with mash feed $(P=0.026)$. An increase in the concentration of VFA in association with mash structure and higher particle size diets has also already been observed (Canibe et al., 2005). In fact, Canibe et al. (2005) showed that feeding a coarse, nonpelleted diet to finishing pigs stimulated the growth of total anaerobes and lactic acid bacteria at the same time as enhancing lactic, acetic, propionic, and butyric acid concentrations in the stomach. However, these authors observed no significant effect of the coarse, nonpelleted diet on VFA concentrations in the cecum and the colon contents. The feeding of a higher particle size mash diet, which results in a slower gastric passage rate leading to an increased proliferation of certain microorganisms of the microbiota associated with a decrease in $\mathrm{pH}$, may explain the changes in E. coli populations and the observed effects on Salmonella excretion (LeBel et al., 2013). LeBel et al. (2013) demonstrated that pigs fed with mash $1,250-\mu \mathrm{m}$ feed had significantly more Bifidobacterium spp. in their feces during the fattening period than pigs receiving pellet feed. Interestingly, the bacteria of the Bifidobacterium spp. genus have often been associated with an increase in antibacterial compounds such as VFA (Mountzouris et al., 2006). Furthermore, results from our study showed that a $1,250-\mu \mathrm{m}$ diet, mash or pellet, is also associated with higher intestinal butyric acid production. The effect of a greater feed particle size on increasing butyric acid concentrations in the cecum and the colon contents found in our study is in accordance with another study on the impact of feed on microbial ecology in pigs (Mikkelsen et al., 2004). Similarly, grinding (coarse vs. fine diets) also resulted in higher acetic $(P<$ $0.001)$, propionic $(P<0.05)$, and butyric $(P<0.10)$ acid concentration in the stomach. These results suggest that change in feed presentation could be associated with microbiota modification (different composition and/or metabolic activities) in the gastrointestinal tract of pigs. No significant effect of a $1,250-\mu \mathrm{m}$ diet was observed for the other VFA examined in our study. These marked effects of mash feed and greater feed particle size on butyric acid levels suggest promising strategies to reduce Salmonella 


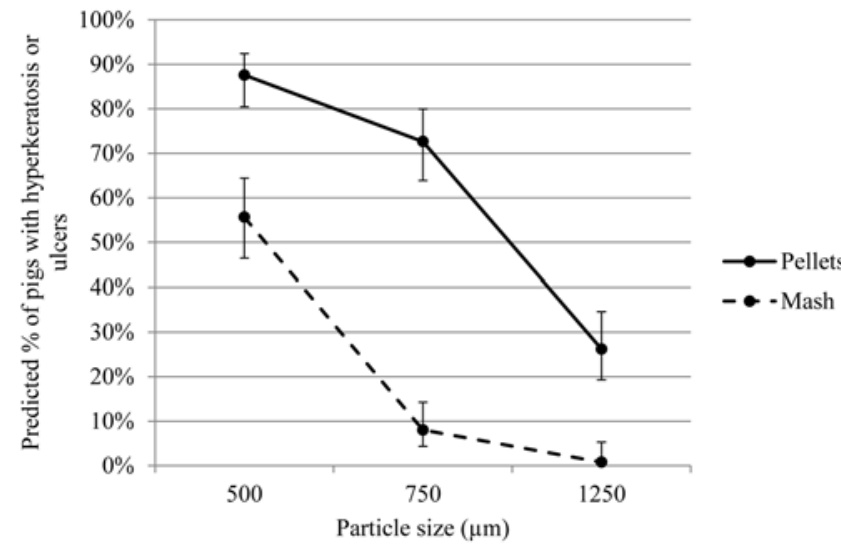

Figure 2. Predicted probabilities of detecting hyperkeratosis or ulcer lesions in pigs at the slaughterhouse according to feed texture and feed particle size. Multiple logistic regression SAS 9.3 (SAS Inst. Inc., Cary, NC)—All predicted probabilities were statistically different $(P<0.01)$ from each other.

spp. colonization, as these have also been reported in a study where coated butyric acid used as a feed supplement decreased the levels of Salmonella Typhimurium excretion and intestinal colonization of piglets (Boyen et al., 2008). Salmonella Typhimurium virulence gene expression, as demonstrated by colonization and invasion, can also be decreased and inhibited in vitro in response to higher butyrate concentrations. A study showed that pigs fed a nonpelleted diet are less susceptible to Salmonella enterica serovar Typhimurium DT12 colonization than pigs fed a pelleted diet (Hedemann et al., 2005). Gantois et al. (2006) showed that the effects of butyric acid on Salmonella spp. are caused by the specific downregulation of Salmonella pathogenicity island 1 (SPI) gene expression. Reduction of the $\mathrm{pH}$ obviously inhibited the dissociation of the VFA, resulting in an increase in the quantity of nondissociated VFA molecules, which seemed to be responsible for bactericidal activity. In the pig colon contents, the $\mathrm{pH}$ may vary between 5.6 and 7.2, depending on the metabolic status, and may also be influenced by feeding. Antibacterial activity is observed only between $\mathrm{pH} 5.6$ and 6.6; above $\mathrm{pH}$ 6.6, the proportion of nondissociated VFA molecules is so low that the antibacterial effect ceases. This may be an explanation for our results in the ileum samples showing no effect of the feed diets on the concentrations of VFA and indicating that the $\mathrm{pH}$ in this section of the gastrointestinal tract was around 7 , suggesting an impact on VFA molecules. For the colon and cecum contents, no statistically significant effects of the feed texture or the feed particle size on the $\mathrm{pH}$ were observed in our study. However, the $\mathrm{pH}$ was always between 5.6 and 6.6. Prohászka $(1980,1986)$ demonstrated that, when compared at identical $\mathrm{pH}$ values, VFA from the rabbit, pig, and human intestinal tract exerted an antibacterial effect of similar intensity on all members of the Enterobacteriaceae family. The antibacterial defense mechanism functioning in the colon is sensitive to all nutritional factors, which alter the $\mathrm{pH}$ of the colon. This underlines the importance of VFA-producing anaerobic bacterial flora, mainly consisting of species of the genus Bacteroides, which is considered to play an important role in the maintenance of gastrointestinal health through the production of butyric acid and the consumption of lactic acid (Guilloteau et al., 2010). It is tempting to speculate that modification of gut flora by modifying feed texture to produce more butyric acid could reduce invasive infections by enteric bacteria such as $E$. coli in growing pigs. Additionally, this study reports an effect of nonpelleted feed on propionic acid levels in different phases of growing pigs. Interestingly, it has recently been shown that propionic acid directly affects Salmonella transcriptional regulators, reducing the bacterial penetration of cultured epithelial cells (Hung et al., 2013). Consequently, enteric bacteria like Salmonella spp. and certain Escherichia coli virotypes may be killed or reduced in number in the gastrointestinal tract by this diet change. However, it is important to evaluate the impact of this alternative strategy on potentially pathogenic subpopulations of $E$. coli to avoid selection pressure on bacteria potentially linked to animal health problems or human disease.

This study is the first to report the effect of feed texture combined with the effect of feed particle size on $E$. coli prevalence in pigs. Total E. coli bacteria were quantified using qPCR because of the ease and rapidity of qPCR compared with traditional culture and because qPCR does not rely on the ability of bacteria to grow. Moreover, qPCR offers the option of storing samples until their analysis, which is an important advantage in field conditions. The results showed that total E. coli load is markedly lowered in both the caecal and colon contents of mash-fed animals. However, quantification of virulence genes revealed that there is no evidence that mash feed affected the proliferation of pathogenic $E$. coli populations, as consistent effects of feed texture and feed particles size were not observed for fae $G$, est $B$, and $c n f l$ gene copies in caecal and colon contents. This raises the question of the biological significance of a greater representation of the subset of $E$. coli-carrying virulence genes in the intestinal contents of mash-fed pigs. Interestingly, another study reported an influence of nonstarch polysaccharides in the diet on swine-pathogenic $E$. coli by quantifying similar virulence factors (Metzler-Zebeli et al., 2010). This shows that diet may have an impact on $E$. coli virulence gene levels. More importantly, virulence genes such as fae $G$ and $e s t B$ are found on plasmids, which can be horizontally transferred (Fernández-Alarcón et al., 2011). Thus, the impact of feed modifications may be different for the quantification of virulence genes carried on plasmids than for the quantification of bacterial population count. This suggests that by reducing the total load of E. coli, the risk of spreading virulence genes in the $E$. coli popula- 
tion and the potential risk of dissemination of pathogenic and/or zoonotic bacteria is decreased. Nevertheless, the present study showed a feed texture effect on the F4 fimbriae gene cecal prevalence as demonstrated by enrichment PCR. The fimbriae F4 was only detectable in the cecum contents of pigs fed a pelleted diet and not in those of pigs fed a mash diet. These fimbriae are an important virulence factor, as they allow the bacteria to bind to specific receptors on intestinal epithelial cells, resulting in colonization and subsequently in the secretion of enterotoxins such as STa, STb, and LT leading to diarrhea in piglets (Melkebeek et al., 2013). As previously mentioned, enterotoxigenic E. coli (ETEC) strains causing diarrhea are more often detected in neonatal and newly weaned pigs (Amezcua et al., 2002; Martins et al., 2010). However, reducing the prevalence and the persistence of ETEC in growing pig herds may contribute to protecting pigs from contamination between production cycles and to reducing the risk of cross-contamination of piglets in the production network. Nevertheless, it would be interesting to compare the effect of the feed texture on animals experimentally infected with ETEC to better understand the mechanism involved to increase animal health and to target strategic production periods in pigs for use of this diet without performance loss.

Consequently, in addition to the pig's gastrointestinal tract health status, this study considered pig performance and economic consequences linked with feed texture and particle size. Our study showed that mash feed generated reduced pig performance to a greater extent than pellet feed and, therefore, had an impact on the profitability of the farms. However, there have been few reports on the study of pigs in intensive conditions and on the impact of particle size on pig performance as in our study. FCR associated with mash feed diets were higher than those associated with pellet feed diets. This supports data from previous studies (Wondra et al., 1995a, 1995b; Mikkelsen et al., 2004), although feed texture did not appear to affect the daily feed intake in pigs receiving the starter feed formulation. Nevertheless, mash feeding could be used at strategic time points at the beginning of the growing phase to reduce the excretion of potential pathogens in pigs and, consequently, to reduce environmental contamination and exposure of pigs and humans, without generating significant effects on the FCR. Further, mash 500$\mu \mathrm{m}$ diets showed lower FCR than the 2 other mash diets. Consequently, the mash 500- $\mu \mathrm{m}$ diet would represent the more economically reliable mash diet with considerable gastrointestinal tract health benefits. Interestingly, for the larger particle size mash diet, no reduction of voluntary intake by the pigs compromised the energy intake during the growing stage, as was observed by Anguita et al. (2007). Gregory et al. (1990) demonstrated that the retention time of food in the digestive tract of the pig simulta- neously increases with the size of the feed particle. Pigs would feel satiated and satisfied for a longer period, resulting in a drop in voluntary intake of the food. However, these analyses are not consistent with the results of our study. Indeed, for the grower diet formulation, pigs fed the $1,250-\mu \mathrm{m}$ particle size diet have average daily consumption indices significantly higher than those of pigs fed the 500- $\mu \mathrm{m}$ diet. Pigs fed the 1,250- $\mu \mathrm{m}$ diet therefore ingested greater quantities, which contributes to reduced growth performance (ADG and FCR).

In conclusion, this study is the first to demonstrate that mash feed diets are associated with higher propionic and butyric acid levels and with a decrease of total E. coli load in both the cecum and the colon contents of growing pigs raised in field-intensive conditions. This approach could participate in reducing E. coli intestinal load and consequently have a beneficial impact on animal health and/or human disease. Contribution to an increase of the microbiological quality and shelf life of the meat product is still to be investigated. Optimistically, economic disadvantages of mash feeding can be countered by optimizing strategies, such as the use of mash feed for curative purposes or in maternity to reduce piglet exposure to potential pathogens and during stressful periods associated with greater vulnerability of animals. Hence, such strategies provide interesting alternatives to increase global health of pigs and consequently help to improve use of antimicrobial agents at the farm level.

\section{APPENDIX}

Diet formulation

\begin{tabular}{|c|c|c|c|c|}
\hline Item & Prestarter & Starter & Grower & Finisher \\
\hline \multicolumn{5}{|l|}{ Ingredient, $\%$} \\
\hline Corn & 47.18 & 47.96 & 53.53 or 54.06 & 52.70 \\
\hline Soybean meal 47\% & 21.00 & 16.60 & 11.40 & 13.00 \\
\hline Corn DDGS ${ }^{1}$ & 15.00 & 20.00 & 20.00 & 20.00 \\
\hline Wheat & 10.00 & 10.00 & 10.00 & 10.00 \\
\hline Animal fat & 2.40 & 2.20 & 1.60 & 1.60 \\
\hline Limestone & 1.50 & 1.60 & 1.60 & 1.30 \\
\hline Lysine sulfate 65 & 0.90 & 0.60 & 0.60 & 0.60 \\
\hline Phosphate dical-21\% & 0.50 & 0.25 & - & - \\
\hline Salt & 0.45 & 0.45 & 0.45 & 0.45 \\
\hline Vit/min premix & 0.15 & 0.15 & 0.15 & 0.13 \\
\hline Threonine & 0.13 & - & - & 0.06 \\
\hline $\begin{array}{l}\text { Methionine hydroxy } \\
\text { analog } 88 \%\end{array}$ & 0.10 & - & - & 0.00 \\
\hline Phytase 1000 FTU & 0.05 & 0.05 & 0.05 & 0.05 \\
\hline Copper chloride $58 \%$ & 0.02 & 0.02 & 0.02 & - \\
\hline \multicolumn{5}{|l|}{ Drug or additive, $\mathrm{mg} / \mathrm{kg}$} \\
\hline Chlortetracycline & 1,210 & - & 1,210 or 0 & - \\
\hline Salinomycin & - & 60 & 0 or 25 & - \\
\hline Ractopamine & - & - & - & 10 \\
\hline
\end{tabular}

${ }^{1} \mathrm{DDGS}=$ distillers dried grains with solubles 


\section{LITERATURE CITED}

Amezcua, R., R. M. Friendship, C. E. Dewey, C. Gyles, and J. M. Fairbrother. 2002. Presentation of postweaning Escherichia coli diarrhea in southern Ontario, prevalence of hemolytic $E$. coli serogroups involved, and their antimicrobial resistance patterns. Can. J. Vet. Res. 66:73-78.

Anguita, M., J. Gasa, M. Nofrarias, S. Martín-Orúe, and J. Pérez. 2007. Effect of coarse ground corn, sugar beet pulp and wheat bran on the voluntary intake and physicochemical characteristics of digesta of growing pigs. Livest. Sci. 107:182-191.

Beaudry, M., C. Zhu, J. Fairbrother, and J. Harel. 1996. Genotypic and phenotypic characterization of Escherichia coli isolates from dogs manifesting attaching and effacing lesions. J. Clin. Microbiol. 34:144-148.

Boyen, F., F. Haesebrouck, A. Vanparys, J. Volf, M. Mahu, F. Van Immerseel, I. Rychlik, J. Dewulf, R. Ducatelle, and F. Pasmans. 2008. Coated fatty acids alter virulence properties of Salmonella Typhimurium and decrease intestinal colonization of pigs. Vet. Microbiol. 132:319-327.

Canibe, N., O. Højberg, S. Højsgaard, and B. B. Jensen. 2005. Feed physical form and formic acid addition to the feed affect the gastrointestinal ecology and growth performance of growing pigs. J. Anim. Sci. 83:1287-1302.

Dozois, C. M., M. Dho-Moulin, A. Brée, J. M. Fairbrother, C. Desautels, and R. Curtiss III. 2000. Relationship between the Tsh autotransporter and pathogenicity of avian Escherichia coli and localization and analysis of the Tsh genetic region. Infect. Immun. 68:4145-4154.

Ewers, C., G. Li, H. Wilking, S. Kiessling, K. Alt, E. M. Antáo, C. Laturnus, I. Diehl, S. Glodde, T. Homeier, U. Böhnke, H. Steinrück, H. C. Philipp, and L. H. Wieler. 2007. Avian pathogenic, uropathogenic, and newborn meningitis-causing Escherichia coli: How closely related are they? Int. J. Med. Microbiol. 297:163-176.

Fernández-Alarcón, C., R. S. Singer, and T. J. Johnson. 2011. Comparative genomics of multidrug resistance-encoding IncA/C plasmids from commensal and pathogenic Escherichia coli from multiple animal sources. PLoS One 6:e23415.

Furrer, B., U. Candrian, and J. Lüthy. 1990. Detection and identification of $E$. coli producing heatlabile enterotoxin type I by enzymatic amplification of a specific DNA fragment. Lett. Appl. Microbiol. 10:31-34.

Gantois, I., R. Ducatelle, F. Pasmans, F. Haesebrouck, I. Hautefort, A. Thompson, J. C. Hinton, and F. Van Immerseel. 2006. Butyrate specifically down-regulates Salmonella pathogenicity island 1 gene expression. Appl. Environ. Microbiol. 72:946-949.

Gregory, P., M. McFadyen, and D. Rayner. 1990. Pattern of gastric emptying in the pig: Relation to feeding. Br. J. Nutr. 64:45-58.

Guilloteau, P., L. Martin, V. Eeckhaut, R. Ducatelle, R. Zabielski, and F. Van Immerseel. 2010. From the gut to the peripheral tissues: The multiple effects of butyrate. Nutr. Res. Rev. 23:366-384.

Hedemann, M. S., L. Mikkelsen, P. Naughton, and B. B. Jensen. 2005. Effect of feed particle size and feed processing on morphological characteristics in the small and large intestine of pigs and on adhesion of Salmonella enterica serovar Typhimurium DT12 in the ileum in vitro. J. Anim. Sci. 83:1554-1562.

Herrero, M., V. De Lorenzo, and J. Neilands. 1988. Nucleotide sequence of the iucD gene of the pColV-K30 aerobactin operon and topology of its product studied with phoA and lacZ gene fusions. J. Bacteriol. 170:56-64.
Hung, C. C., C. D. Garner, J. M. Slauch, Z. W. Dwyer, S. D. Lawhon, J. G. Frye, M. McClelland, B. M. Ahmer, and C. Altier. 2013. The intestinal fatty acid propionate inhibits Salmonella invasion through the post-translational control of HilD. Mol. Microbiol. 87:1045-1060.

Juteau, P., D. Tremblay, R. Villemur, J.-G. Bisaillon, and R. Beaudet. 2004. Analysis of the bacterial community inhabiting an aerobic thermophilic sequencing batch reactor (AT-SBR) treating swine waste. Appl. Microbiol. Biotechnol. 66:115-122.

Knudsen, K. E. B., A. Serena, N. Canibe, and K. S. Juntunen. 2003. New insight into butyrate metabolism. Proc. Nutr. Soc. 62:81-86.

LeBel, P., P. Fravalo, J. Longpré, É. Yergeau, B. Laplante, and A. Letellier. 2013. Digestive microbiota changes during application of an effective, feed presentation based, mitigation option against Salmonella shedding in pigs. In: 10th Int. Conf. on the Epidemiology and Control of Biological, Chemical and Physical Hazards in Pigs and Pork, Portland, ME. p. 147-150

Lo Fo Wong, D., J. Dahl, H. Stege, P. J. van der Wolf, L. Leontides, A. von Altrock, and B. M. Thorberg. 2004. Herd-level risk factors for subclinical Salmonella infection in European finishing-pig herds. Prev. Vet. Med. 62:253-266.

Lortie, L.-A., J. D. Dubreuil, and J. Harel. 1991. Characterization of Escherichia coli strains producing heat-stable enterotoxin b (STb) isolated from humans with diarrhea. J. Clin. Microbiol. 29:656-659.

Maluta, R. P., J. M. Fairbrother, A. E. Stella, E. C. Rigobelo, R. Martinez, and F. A. de Avila. 2014. Potentially pathogenic Escherichia coli in healthy, pasture-raised sheep on farms and at the abattoir in Brazil. Vet. Microbiol. 169:89-95.

Martins, R. P., M. C. da Silva, V. Dutra, L. Nakazato, and D. da Silva Leite. 2010. Prevalence of enterotoxigenic and Shiga toxin-producing Escherichia coli in pigs slaughtered in Mato Grosso, Brazil. J. Infect. Dev. Ctries. 5:123-127.

Melkebeek, V., B. M. Goddeeris, and E. Cox. 2013. ETEC vaccination in pigs. Vet. Immunol. Immunopathol. 152:37-42.

Metzler-Zebeli, B. U., S. Hooda, R. Pieper, R. T. Zijlstra, A. G. van Kessel, R. Mosenthin, and M. G. Gänzle. 2010. Nonstarch polysaccharides modulate bacterial microbiota, pathways for butyrate production, and abundance of pathogenic Escherichia coli in the pig gastrointestinal tract. Appl. Environ. Microbiol. 76:3692-3701.

Mikkelsen, L. L., O. Højberg, and B. B. Jensen. 2007. Coarse structured feed stimulates members of the genera Lactobacillus and Mitsuokella as well as propionate and butyrate producers in the pig stomach. Livest. Sci. 109:153-156.

Mikkelsen, L. L., P. J. Naughton, M. S. Hedemann, and B. B. Jensen. 2004. Effects of physical properties of feed on microbial ecology and survival of Salmonella enterica serovar Typhimurium in the pig gastrointestinal tract. Appl. Environ. Microbiol. 70:3485-3492.

Mountzouris, K. C., C. Balaskas, F. Fava, K. M. Tuohy, G. R. Gibson, and K. Fegeros. 2006. Profiling of composition and metabolic activities of the colonic microflora of growing pigs fed diets supplemented with prebiotic oligosaccharides. Anaerobe 12:178-185.

Ngeleka, M., J. Pritchard, G. Appleyard, D. M. Middleton, and J. M. Fairbrother. 2003. Isolation and association of Escherichia coli AIDA-I/STb, rather than EAST1 pathotype, with diarrhea in piglets and antibiotic sensitivity of isolates. J. Vet. Diagn. Invest. 15:242-252. 
O'Connor, A., T. Denagamage, J. Sargeant, A. Rajić, and J. McKean. 2008. Feeding management practices and feed characteristics associated with Salmonella prevalence in live and slaughtered market-weight finisher swine: A systematic review and summation of evidence from 1950 to 2005. Prev. Vet. Med. 87:213-228.

Ojeniyi, B., P. Ahrens, and A. Meyling. 1994. Detection of fimbrial and toxin genes in Escherichia coli and their prevalence in piglets with diarrhoea. The application of colony hybridization assay, polymerase chain reaction and phenotypic assays. Zentralbl. Veterinarmed. B 41:49-59.

Prohászka, L. 1980. Antibacterial effect of volatile fatty acids in enteric $E$. coli + infections of rabbits. Zentralbl. Veterinarmed. B. 27:631-639.

Prohászka, L. 1986. Antibacterial mechanism of volatile fatty acids in the intestinal tract of pigs against Escherichia coli. Zentralbl. Veterinarmed. B 33:166-173.
Standard, A. 2003. Method of determining and expressing fineness of feed materials by sieving. ASABE, St. Joseph, MI.

Stecher, B., and W.-D. Hardt. 2011. Mechanisms controlling pathogen colonization of the gut. Curr. Opin. Microbiol. 14:82-91.

Wondra, K., J. Hancock, K. Behnke, R. Hines, and C. Stark. 1995a. Effects of particle size and pelleting on growth performance, nutrient digestibility, and stomach morphology in finishing pigs. J. Anim. Sci. 73:757-763.

Wondra, K., J. Hancock, K. Behnke, and C. Stark. 1995b. Effects of mill type and particle size uniformity on growth performance, nutrient digestibility, and stomach morphology in finishing pigs. J. Anim. Sci. 73:2564-2573.

Woodward, M., P. Carroll, and C. Wray. 1992. Detection of enteroand verocyto-toxin genes in Escherichia coli from diarrhoeal disease in animals using the polymerase chain reaction. Vet. Microbiol. 31:251-261. 